\title{
Sociedad, Utopía y EdUCACiÓN EN IvÁN ILLICH
}

\author{
Marcos Santos Gómez ${ }^{1}$ \\ Universidad de Granada, España.
}

\begin{abstract}
En este artículo resaltamos la conexión entre la crítica a la escolarización de Iván Illich y su contundente crítica a la sociedad de consumo y la tecnificación de la vida humana. Revisamos sus argumentos y los relacionamos con algunos movimientos filosóficos y pensadores del siglo $X X$, también críticos con las formas de vida heredadas de una cierta versión de la Ilustración.
\end{abstract}

Descriptores: Illich, Ivan. Educación. Crítica. Utopías.

\section{Iván Illich: la mirada inocente.}

Tván Illich tenía la virtud de ver donde muchos no vemos, tal vez debido a su capacidad para mirar como los niños, con la inocencia propia de ellos. Cuando Illich aborda el estudio de la sociedad contemporánea y de sus instituciones realiza una descripción desde fuera, desde una posición "ingenua" que le ayuda a ver las cosas que suelen pasar desapercibidas por el hábito y los prejuicios. Su originalidad a la hora de estudiar la institución escolar, como cuando estudia otras instituciones contemporáneas, viene dada por un enfoque descriptivo-fenomenológico que lo dota de una ácida y explosiva inocencia. Así, afirma:

Trato de describir sencillamente lo que veo como si fuera un marciano lo que constituye el concepto de escolaridad. Es un proceso de clasificación de toda la sociedad en grupos, en gremios alrededor de otro personaje, a quien se le da muchos

1 Docente do Departamento de Pedagogía, Facultad de Ciencias de la Educación, Universidad de Granada, Campus Universitario de Cartuja, S/N, CEP 18071, Granada, España. Endereço Eletrônico: masantos@ugr.es 


\section{Marcos Santos Gómez}

nombres diferentes pero que esencialmente es distinto de los demás personajes reunidos porque participó muchas más horas en estas reuniones específicas por edades. (Illich, 1975, p. 17)

En efecto, en este artículo vamos a estudiar hacia dónde nos conduce esa mirada que lleva a cabo nuestro autor, cuando la enfoca concretamente hacia lo que ocurre en nuestras escuelas y sistemas educativos. Intentaremos resumir su viaje, para comprenderlo y llegar adonde él llegó.

La mirada inocente de Iván Illich supone, sobre todo, una percepción muy negativa del progreso tecnológico y el mundo moderno. Pero hemos de destacar que su crítica no es un hecho solitario y nos parece, aun más, que corresponde a un sentimiento bastante generalizado a lo largo del dramático siglo pasado y que hoy ha cuajado, por ejemplo, en los movimientos ecologistas. La Escuela de Frankfurt, el freudomarxismo, los movimientos contraculturales de los años sesenta y setenta, etc., llegaron a una conclusión similar, desde enfoques diferentes: nos hemos alejado de un modelo humano de sociedad. Es decir, vivimos existencias deshumanizadas que, en el fondo, nadie habría querido vivir, si hubiera podido elegirlo.

La crítica radical a la escuela de Illich se relaciona, sobre todo, con el cuestionamiento de un modelo de vida. Las alternativas que este autor sugiere procuran aproximarse a un modelo de salud humana, es decir, a un tipo de organización social en el que nuestras existencias serían, supuestamente, más felices y provechosas. Pero siendo consecuente con el carácter utópico de su pensamiento, jamás detalla con exactitud el dibujo de esa futura y posible salud humana.

En los temas estudiados por nuestro utópico pensador se refleja la vastedad de los campos de aplicación de sus teorías. A todas luces, era un alma inquieta y capaz de argumentar con lógica las hipótesis en apariencia más extravagantes, dando la sensación de que siempre escribía dotado de un gran sentido común. Desde luego, la idea básica y principal que caracteriza a todo su pensamiento es el cuestionamiento de la sociedad dirigida por expertos-técnicos y la consecuente profesionalización de la enseñanza. Con esto se situó en un punto de vista que representaba una crítica tanto a la política de los países capitalistas, como a la desarrollada en los países comunistas. Así, leemos que afirma en una entrevista: 
creo haber podido observar que en cada campo hasta ahora analizado, el instrumento material de producción puede adquirir ciertas características meramente técnicas por las cuales impone, a toda sociedad que adopte este medio como instrumento de producción, unas relaciones sociales profundamente explotadoras y altamente injustas. Este es mi punto de partida. (Illich, 1975, p. 16)

Nuestro autor revisó los que consideró grandes mitos de nuestra civilización, para propugnar lo que podríamos denominar una revitalización de la propia vida. Esta revitalización de la existencia pasa por aligerarla de los distintos corsés institucionales que, según él, la violentan. La ciencia, la escuela o la medicina, en cuanto saberes institucionalizados, imponen un corsé al entendimiento que anula la interacción humana espontánea y original. En definitiva, las instituciones no sólo no nos ayudan a vivir una vida mejor, sino que, enfatiza Illich, nos sustraen por completo la posibilidad de ella. Así lo expresa con toda claridad:

No somos capaces de concebir más que sistemas de hiper-instrumentalización para los hábitos sociales, adaptados a la lógica de la producción en masa. Casi hemos perdido la capacidad de soñar un mundo en donde la palabra se tome y se comparta, en donde nadie pueda limitar la creatividad del prójimo, en donde cada uno pueda cambiar la vida. (Illich, 1978, pp. 32-33)

Además, la crítica de Illich a la escolarización guarda estrecha relación con la crítica que también hace al consumismo. Así lo afirma un editor de su obra y amigo suyo: "Detrás de las comprobaciones, rápidamente simplificadas por sus seguidores, como 'la escuela desescolariza', 'el hospital enferma', 'el automóvil obstruye la circulación', se encuentra una notable crítica al 'progreso' y a aquello que lo legitima, la satisfacción de las supuestas "necesidades"” (Paquot, 2003, p. 28). En efecto, Illich realiza un análisis y genealogía de las diversas necesidades que asumimos en nuestra época:

El estudio de la invención de las necesidades estandarizadas y válidas para todos ocupará a Ivan Illich durante varios años y lo obligará, en el transcurso de ellos, a establecer otras genealogías como las de "ser humano", "vida", "persona", "género", "salud" ..., etc., de donde resulta una evolución en la historia de Occidente. (Paquot, 2003, p. 28)

Desde luego, las propuestas de Illich tienen sentido dentro de una concepción específica del hombre. Para él, el ser humano es, fundamentalmente, 
persona libre que se realiza, activa y creativamente, colaborando con los demás. Nos lo muestra idealmente viviendo con mayor austeridad que en nuestras actuales sociedades de consumo, pero a cambio, con un mayor dominio sobre su destino vital y entorno. Se trata de un ser humano que vive con menos comodidad material que en la sociedad consumista, pero participa en su cultura, realizando su potencial de creatividad y libertad. Así, dice: "El hombre reencontrará la alegría de la sobriedad y de la austeridad, reaprendiendo a depender del otro, en vez de convertirse en esclavo de la energía y de la burocracia todopoderosa" (Illich, 1978, p. 31).

Illich argumenta con frecuencia que al hombre no le es posible la realización como tal en un mundo consumista: "Una sociedad que define el bien como la satisfacción máxima, por el mayor consumo de bienes y servicios industriales, del mayor número de gente, mutila en forma intolerable la autonomía de la persona" (Illich, 1978, p. 29). Para nuestro autor, "Poco a poco las instituciones no sólo han conformado nuestra demanda, sino que también han dado forma a nuestra lógica, es decir, a nuestro sentido de la medida. Primero se pide lo que produce la institución, pronto se cree no poder vivir sin ello" (p. 37).

En definitiva, las instituciones, que indiscutiblemente nos han hecho la vida más cómoda en lo material, constituyen un arma de doble filo, porque generan en todos nosotros una paralizante dependencia y pasividad. Nos acabamos acostumbrando a que ellas nos organicen y faciliten la vida, pagando el precio de acabar sometiéndonos a su lógica. Será desde esta convicción que llevará a cabo su crítica a la escolarización. Una crítica que, como hemos dicho, parte de una nueva manera de ver las cosas aparentemente más normales y habituales, del ejercicio de una mirada inocentemente original.

\section{Análisis de la institucionalización del saber. Razones para la desescolarización de la sociedad.}

Al abordar Iván Illich directamente la institución escolar, con la explosiva ingenuidad que lo caracteriza, se esfuerza en mostrarnos que la transmisión del conocimiento y la cultura, que había discurrido durante siglos con espontaneidad vital fuera de la escuela y sin necesidad de ella, hoy ha quedado 
restringida al interior de las paredes del aula. Por eso, en cuanto resultado de un proceso histórico, resulta cuestionable la necesidad de ser educados escolarmente.

Haría falta elaborar una historia de la necesidad de educación (más que una historia de la educación). Como señala Antoni Tort (2003):

[Illich] Consideraba que la historia de la educación que se hace en el mundo sigue sin investigar cómo nace históricamente la necesidad de educación y sólo analiza modalidades educativas, sin cuestionarse la propia existencia de las instituciones y los sistemas. Creía que no hay suficientes estudios "sobre" la educación, y que convendría analizar con más profundidad la historia de cómo emerge una realidad social en el seno de la cual la educación es percibida como una necesidad fundamental. (p. 81)

Iván Illich constata que el ecosistema específico de la escuela se halla lejos del entorno real en donde fluye la vida y somos personas. Este alejamiento se refleja, sintomáticamente, en una escisión de la cultura humana entre lo popular, por una parte, y lo académico o escolar, por otra. $\left({ }^{2}\right)$ De modo que nuestro autor afirma que:

La existencia misma de escuelas obligatorias divide cualquier sociedad en dos ámbitos: ciertos lapsos, procesos, tratamientos y profesiones son "académicos" y "pedagógicos", y otros no lo son. Así, el poder de la escuela para dividir la realidad social no conoce límites: la educación se hace no terrenal, y el mundo se hace no educacional. (Illich, 1974, p. 39)

Siguiendo un símil del propio Illich, en la escuela se intenta regular la producción en masa de saber, mediante grados parecidos a los que la alquimia logra en su purificación de la materia.

Dentro del proceso alquimista, la educación se convierte en la búsqueda de aquello de donde nacerá un nuevo tipo de hombre, requerido por el medio, moldeado por la magia científica. Pero sea cual haya sido el precio pagado por las sucesivas genera-

2 El autor del presente ensayo ha estudiado en otro trabajo la escisión cultural entre lo popular y lo escolar-académico. En dicho artículo, sin referirse entonces a Illich y desde otra perspectiva similar, aplicó el enfoque de Boudieu y la Pedagogía crítica para indagar posibles causas de esta extraña dicotomía y apuntar de manera general hacia una alternativa que finalmente reconcilie lo popular con lo académico (Santos, 2006b). 


\section{Marcos Santos Gómez}

ciones, se reveló cada vez de nuevo que la mayoría de los alumnos no eran dignos de alcanzar los más altos grados de la iluminación, y era preciso excluirlos del juego, por ineptos para llevar la "verdadera" vida, ofrecida en ese mundo creado por el hombre. (Illich, 1978, p. 38)

Esta separación radical de lo vital y lo académico que se daría en la educación-alquimia acarrearía, también, una nueva consecuencia perniciosa, desde el punto de vista de nuestro autor: la jerarquización de los seres humanos.

Según el parecer de nuestro autor, las relaciones jerárquicas y la división excluyente entre los hombres resultan brutalmente maligna. Es éste un aspecto de su pensamiento que nos remite también a otros autores de la filosofía y la pedagogía del siglo XX: Fromm, Reich, Paulo Freire, A. S. Neill, etc. En esta línea, que entiende la salud humana como "horizontalización" de las relaciones humanas (Santos, 2006a), se inserta la perspectiva de Iván Illich.

Así pues, la enseñanza obligatoria, que se ha justificado normalmente como promotora de igualdad y de la mejora generalizada de individuo y sociedad, a juicio de Illich produce en realidad la jerarquización social y la inhibición de la participación de los ciudadanos en la cultura. Pero no sólo eso, sino que también los prepara para la sociedad consumista propia de nuestro tiempo. Illich lo expresa a menudo:

La escuela es el rito de iniciación que conduce a una sociedad orientada al consumo progresivo de servicios cada vez más costosos e intangibles, una sociedad que confía en normas de valor de vigencia mundial, en una planificación en gran escala y a largo plazo, en la obsolescencia continua de sus mercancías basada en el ethos estructural de mejoras interminables: la conversión constante de nuevas necesidades en demandas específicas para el consumo de satisfactores nuevos. (Illich, et al., 1977, p. 15)

Por tanto, los problemas relacionados con la educación no se solucionarían con mejoras parciales, mayores inversiones, el uso de nuevas didácticas y ni siquiera con el fomento del trabajo cooperativo o el papel activo de los niños en el aula. El quid de la cuestión estribaría, desde la perspectiva radical que estamos exponiendo, en comprender que el problema es la propia escuela en cuanto tal, en lo que supone de ritualización y profesionalización del proceso de enseñanza-aprendizaje que inevitablemente conlleva. El malestar de la escuela reside justo en la suplantación de un proceso más sencillo y natural. 
Porque, como nos señala el pensador austriaco: "Lo principal del aprendizaje sobreviene casualmente, e incluso el aprendizaje más intencional no es el resultado de una instrucción programada" (Illich, 1974, p. 25).

Refiriéndose a quienes proponen mejoras dentro de la institución escolar Illich afirma:

Creo que todos estos críticos yerran debido a que no toman en cuenta el aspecto ritual de la enseñanza, como lo he llamado en otro trabajo y que en éste me propongo denominar el "curriculum oculto", la estructura que sirve de base de sustento a lo que se conoce como "efecto de certificación". (Illich, et al., 1977, p. 17)

La escuela hace y enseña lo contrario de lo que afirma hacer y enseñar. No es el curriculum oficial el que describe lo que principalmente aprende el niño en ella, sino el curriculum oculto:

Todos los niños aprenden, gracias al curriculum oculto, que el conocimiento económicamente valioso es el resultado de la enseñanza institucionalizada y que los títulos sociales son resultado del rango que se ocupa en el proceso burocrático. Así, el curriculum oculto transforma el curriculum visible en una mercancía y hace de su adquisición la forma de riqueza más segura. (pp. 18-19)

Es decir, el conocimiento se convierte, en la escuela y por ella, en una mercancía que supone una suerte de posesión y riqueza material para quien la obtiene.

La interpretación de la necesidad de aprender como una demanda de escolaridad y la transformación de la cualidad de crecer y desarrollarse en la etiqueta de una educación profesional, convierten el significado de la palabra conocimiento, de un término que indica intimidad, intercambio con otras personas y experiencia vital, en uno para designar productos profesionalmente empacados, títulos cotizables en el mercado y valores abstractos. La escuela ha ayudado a dar alas a tal interpretación. (Illich, et al., 1977, p. 20)

Sin embargo, el conocimiento es, según nuestro autor, algo fundamentalmente dinámico, que se halla en continua transformación.

La consecuencia del paso por la escuela sería una suerte de alejamiento del hombre de su propia esencia (sociable y fraternal), resultando de ello una mutilación, como nuestro autor subraya en numerosas ocasiones: 


\section{Marcos Santos Gómez}

Una expansión del concepto de alienación podría permitirnos ver que en una economía fundada en la prestación de servicios, el hombre es separado de lo que puede hacer lo mismo que de lo que puede producir; que ha entregado su mente y su corazón a un tratamiento mutilante en forma más completa de lo que ha vendido los frutos de su trabajo. (p. 21)

El sujeto así alienado vive la reglamentación del saber como una opresión anónima, cuya fuente le resulta invisible e imposible de señalar. Es la consecuencia de la sociedad del experto (tecnocracia) en la que los ciudadanos han aprendido inconscientemente que su acceso a la realidad tiene que ser mediatizado:

El consumidor de conocimientos precocinados aprende a reaccionar ante el conocimiento que ha adquirido más que ante la realidad, de la cual un grupo de expertos lo ha abstraído. Su acceso a la realidad es controlado siempre por un terapeuta, y si el alumno acepta tal control como cosa natural, su cosmovisión se convierte en algo higiénico y neutral y él en una persona políticamente impotente. (p. 29)

A continuación, vamos a comparar estas ideas de Illich que hemos expresado, con algunas pedagogías radicales que, sin llegar tal vez a sus conclusiones, pueden enriquecer esta discusión sobre el papel de la escuela y las posibles alternativas que cabría imaginar.

\section{Alienación, autoritarismo y escuela desde la concepción de la pedagogía no directiva.}

Que la educación escolar puede tener un potente efecto alienador no ha sido una crítica tan sólo de los autores de la desescolarización (Goodman, 1976; Holt, 1982; Reimer, 1981). También lo encontramos, con argumentos más o menos próximos, en Ferrière (1982), la educación liberadora de Paulo Freire (1992) y la pedagogía y la praxis de la escuela "Summerhill" que fundara el escocés A. S. Neill (1994). En todos ellos encontramos destacado el hecho de que en las formas más directivas de educación, la actividad y la creatividad se convierten en privilegio exclusivo del experto, en cuya autoridad descansa el conocimiento y la transmisión del mismo. Así, educar llega a ser una actividad unidireccional en la que el educando adopta un comportamiento pasivo y es "dirigido" en el proceso de su propio crecimiento y aprendizaje. 
Desde luego, cuando estos pedagogos cuestionan la autoridad del maestro, a menudo tienen en mente una concepción de escuela autoritaria o directiva que no siempre se corresponde con la idea común que se suele tener del autoritarismo. Es preciso resaltarlo. No siempre el autoritarismo que ellos critican equivale al expresado por el lema "la letra con sangre entra". De hecho, para muchos de ellos

Las escuelas del siglo XX han desarrollado un tipo de autoridad anónima que prepara a los estudiantes para la manipulación a manos de una sociedad propagandista y burocrática. La escuela tradicional era un ejemplo perfecto de autoridad abierta; el maestro se enfrentaba directamente a los estudiantes con su propio poder, y los estudiantes siempre eran conscientes de dónde partía el poder. El aspecto favorable de esta situación era que si los estudiantes deseaban rebelarse y pedir su libertad, podían identificar la fuente del poder y reaccionar ante ella. En el siglo XX se introdujeron en las escuelas formas anónimas de autoridad por medio de técnicas psicológicas más sofisticadas. Estas formas de control han hecho mucho más difíciles la comprensión del hecho de la manipulación y la identificación de la fuente de control." (Spring, 1987, p. 31)

En efecto, sobre el concepto de "autoridad" hay bastante que puntualizar. En este sentido, Erich Fromm, en su prólogo al primer libro que escribió Neill sobre Summerhill, se pregunta si es un error proponer una educación que no emplee la fuerza. El aparente fracaso de la educación permisiva y la escuela carente de disciplina, nos puede conducir a rechazar la ausencia de autoridad sancionadora. Pero la cuestión es más sutil. Así, precisa Fromm (1994):

Yo creo que la idea de libertad para los niños no era errónea, pero sí que la idea de la libertad ha sido pervertida casi siempre. Para examinar con claridad este asunto, debemos empezar por comprender la naturaleza de la libertad, y para ello debemos distinguir entre autoridad evidente y autoridad anónima. (p. 9)

Su reflexión conduce a una definición de la libertad que se relaciona con la psique y la vida afectiva. En El Miedo a la Libertad (Fromm, 1976) explica cómo la libertad que surge en el proceso de individuación puede constituir una pesada carga para el sujeto, que pagaría como precio el padecimiento del amargo sentimiento de la separatidad. Así pues, la libertad puede asustar al hombre, porque teme hallarse a solas con las riendas del propio destino, verse como solitario responsable de sí mismo. Con el fin de evitar esa angustiosa soledad, los seres humanos buscan maneras de regresar a la unidad primigenia 


\section{Marcos Santos Gómez}

que se vivía en el útero materno. Es decir, intentan regresar a la existencia anterior al surgimiento del individuo autónomo.

Una forma recurrente de regresar a este paraíso originario ha sido, en los pueblos y en los individuos, el sometimiento más o menos consciente a una autoridad, cobijándose bajo su manto y amparo, de modo que decae el peso que la libertad coloca sobre el sujeto. $Y$ es a partir de esta profunda necesidad como se constituye y recibe su fuerza la "autoridad anónima". El autoritarismo, con uno u otro matiz, se aprovecha de la necesidad de "guía" producida por el miedo que la libertad puede generar en los seres humanos.

La autoridad anónima es mucho más penetrante y eficaz que la coerción ejercida por la fuerza. El suyo es un poder basado en los temores asociados con la condición humana, o sea, en los miedos atávicos que los hombres soportan como precio de su libertad y autonomía. En palabras de Fromm (1994):

La autoridad anónima tiende a ocultar que se emplea la fuerza. La autoridad anónima finge que no hay autoridad, que todo se hace con el consentimiento del individuo. Mientras que el maestro del pasado le decía a Juanito: "Debes hacer esto. Si no, te castigaré", el maestro de hoy dice: "Estoy seguro de que te gustará hacer esto." Aquí la sanción para la desobediencia no es el castigo corporal, sino el gesto ceñudo del padre o, lo que es peor, la sensación de no estar "ajustado", de no obrar como obra de la mayoría. La autoridad evidente empleaba la fuerza física; la autoridad anónima emplea el manejo psíquico. (p. 10)

Y la autoridad así ejercida es mucho más efectiva.

Según Fromm el moldeamiento que va ejerciendo esa autoridad anónima obedecería en último término a la lógica del capitalismo consumista, porque satisface la necesidad que tiene el sistema económico de crear seres adecuados al mismo, individuos que crean querer consumir cada vez más.

Nuestro sistema ha de crear hombres de gustos uniformes, hombres que puedan ser influidos fácilmente, hombres cuyas necesidades puedan preverse. Nuestro sistema necesita hombres que se sientan libres e independientes, pero que, sin embargo, hagan lo que se espera de ellos, hombres que encajen en el mecanismo social sin fricciones. (Fromm, 1994, p. 10)

O sea, en el mundo capitalista de consumo la autoridad es una autoridad sin nombre que practica la persuasión y la sugestión antes que la fuerza, 
para conseguir un tipo específico de persona que viene requerido por el sistema económico.

Hemos de tener presente que la violencia por parte de los alumnos también participa de una lógica autoritaria. Porque si el niño hace todo lo que quiere, no existe libertad real, sino una degeneración de las relaciones humanas y la educación que Neill denomina "libertinaje" o "licencia". De algún modo, el niño se ha sentido esclavo, ha percibido que se le ha conducido sutilmente contra sí mismo, hacia valores extraños, etc. Ha aprendido que las relaciones humanas consisten en abusar unos de otros. Y si puede, abusa él también. Ha interiorizado la lógica del poder y el dominio.

Para que se diese la auténtica libertad, el niño no puede carecer de derechos, pero tampoco debe tenerlos todos. Es una sutil línea que se expresa en el elocuente y conocido lema que enuncia Neill (1994): "La libertad significa hacer lo que se quiera mientras no se invada la libertad de los demás. El resultado es la autodisciplina" (p. 105). La libertad requiere, por tanto, el aprendizaje de la propia responsabilidad y la convivencia. Con la claridad que lo caracteriza, Neill (1999) lo expresa: "el autocontrol implica la capacidad para pensar en los demás, para respetar el derecho de los demás.... El hombre autocontrolado no se sienta a la mesa con otros comensales y se sirve la mitad del contenido de la ensaladera" (pp. 22-23). Y el niño, para ser libre, debe aprender este autocontrol que parte de la estimación solidaria del otro. Éste es el objetivo supremo de escuelas como Summerhill.

La conexión entre la educación en la escuela y la transformación crítica de la sociedad es enfatizada por Neill. Las palabras del pedagogo escocés en la introducción a su libro más conocido son bastante expresivas:

Todos los crímenes, todos los odios, todas las guerras, pueden reducirse a infelicidad. Este libro intenta hacer ver cómo nace la infelicidad, cómo arruina las vidas humanas, y cómo pueden criarse los niños de manera que no se presente nunca una proporción crecida de esa infelicidad. (Neill, 1994, p. 17)

Más adelante, señala: "La civilización está enferma y es desgraciada, y yo sostengo que la raíz de todo ello es la familia sin libertad" (Neill, 1994, p. 95). y "No hay nunca niños problema; sólo hay padres problema. Quizás fuera mejor decir que sólo hay una humanidad problema" (p. 95). No es posi- 
ble, desde esta perspectiva, diferenciar tajantemente la escuela y la sociedad. Hay una conexión imposible de desligar y que se debe contemplar a la hora de desarrollar, por ejemplo, diagnósticos o terapias para el niño. Por esto mismo, toda curación debe considerar la salud o la enfermedad de la sociedad al completo, en la línea del pensamiento y la psicología, también, de Erich Fromm o Wilhelm Reich.

Pero Iván Illich llega más lejos aun. Como afirma el estudioso de su obra Antoni Tort (2003):

Para Illich, no es posible convertir las escuelas, instituciones burocratizadas, actuales y manipulativas, en otras de carácter convivial, humanizadoras, donde las personas actúen autónomamente. Las propuestas coetáneas a la desescolarización, desde el auge de Summerhill hasta la pedagogía institucional, en ningún caso suponen, para Illich, un preludio de revolución educativa. (p. 83)

Subraya la necesidad de no dejarnos seducir por reformas de la escuela que no cuestionan a la propia institución escolar. La enfermedad es ella misma. Mientras exista escuela, por más libre que sea, y en esto nuestro autor supera con claridad los planteamientos de Neill, se sigue generando una personalidad dependiente, un espíritu esclavo. Las formas solapadas de autoritarismo son imposibles de eliminar de toda educación impartida bajo el modelo "profesor-alumno". Por eso, la escuela inevitablemente crea adicción y enseña la necesidad de ella misma. El niño educado en escuelas como Summerhill puede demandar toda la vida la escuela "libre" en la que se educó, en una sociedad que, además, marcha por derroteros brutalmente contrarios. Como afirma Illich: "Los graduados de la escuela libre son fácilmente reducidos a la impotencia al enfrentarse a la vida en una sociedad que no se parece en nada a los invernaderos en que han sido cultivados" (Illich, et al., 1977, p. 26).

Para Illich resulta fundamental entender la escuela como el producto de una forma concreta, y criticable, de sociedad humana, concluyendo que es necesaria una transformación profunda y general que abarque toda la cultura humana y acabe superando la propia idea de "escuela" o "escolarización". 


\section{La alternativa utópica a la sociedad escolarizada.}

La utopía que, a nuestro juicio, preside todo el discurso transgresor de Illich es la de una cultura en la que todos los hombres seamos protagonistas y artífices. Sus propuestas persiguen la devolución a los seres humanos de su capacidad natural de crear cultura y de participar en ella. Ésta es la nota definitoria del hombre crítico, como también describen Giroux y McLaren (1998): "Ser crítico ... significa desechar cualquier distancia cognitiva puramente contemplativa, sobre y por encima del mundo, pero para afrontar la contingencia del presente con la esperanza radical" (p. 227). El enfoque crítico de la educación aspira a una praxis educativa en la que no haya escisión entre el pensamiento y la acción. Así, podemos leer: "Me estoy refiriendo aquí acerca de una praxis en la cual el sujeto cognoscente es un sujeto actuante, una praxis en la cual asumimos la responsabilidad de la historia y de una visión del mundo que "aún no es"” (p. 227).

La educación escolar ha complicado las cosas, desde la perspectiva del austriaco, reglamentando e institucionalizando el mecanismo natural de la continua re-creación de cultura. El intento de Illich consiste en la recuperación de la horizontalidad entre los seres humanos, perdida por culpa de la escolarización del modo que hemos explicado en líneas anteriores, de manera que conectemos de nuevo con la transitividad que nos es propia. (Freire, 1989, p. 53)

Como hemos visto, Illich subraya la función esencialmente ideológica de la institución escolar, en la medida en que contribuye a la interiorización de la verticalidad que caracteriza a nuestra sociedad de consumo, fortaleciéndola y justificándola. $\left({ }^{3}\right)$ Los títulos expedidos en los distintos niveles de la edu-

3 En cierta ocasión, debatiendo con Paulo Freire, Illich propone la siguiente descripción de lo que se entiende implícitamente por “educación”: “Educación -lo que hoy se llama educación- es esencialmente una producción planeada de aprendizaje en otro. Y si no les gusta la palabra 'producción', entonces, provocación planeada de libertad en otro -como opuesta al espontáneo, al autónomo descubrimiento que surge del encuentro entre usted y yo" (Illich \& Freire, 1975, p. 46). Esta definición no implica solamente a la denominada "educación formal", sino que en muchos aspectos, también a la "educación informal” y a la "educación no formal”. En realidad, se trata de algo más básico que podíamos denominar "mentalidad escolar”. Desde ésta, cabe entender, por ejemplo, la figura de un ministro de educación, que para Illich resulta ilógica. "Llamo aquí ministro de educación a un personaje de fábula, quiero decir, a la institución que 


\section{Marcos Santos Gómez}

cación formal van catalogando a los individuos, que sienten el conocimiento como una posesión que otorga prestigio, excluyendo de la sabiduría a quien no los posee y absolutizando su ignorancia. Así, afirma: "Una vez que se ha escolarizado a las personas con la idea de que los valores pueden producirse y medirse, tienden a aceptar toda clase de clasificaciones jerárquicas" (Illich, 1974, p. 59). En este sentido, se puede entender que existe una forma escolar de ver y entender el mundo, es decir, hay una mentalidad escolar cuyo aprendizaje resulta la principal función oculta de la escuela.

La consecuencia de la escolarización, desde la perspectiva de Illich, es atroz. Porque a la vez que el sujeto educando aprende a integrarse en la sociedad estratificada y de consumo, emprende un camino de honda infelicidad que lo aleja de sí mismo y frustra sus verdaderas necesidades:

La escuela hace a la alienación preparatoria para la vida, privando así a la educación de realidad y al trabajo de creatividad. La escuela prepara para la alienante institucionalización de la vida al enseñar la necesidad de ser enseñado. Una vez que se aprende esta lección, la gente pierde su incentivo para desarrollarse con independencia; ya no encuentra atractivos en relacionarse y se cierra a las sorpresas que la vida ofrece cuando no está predeterminada por la definición institucional. (Illich, 1974, p. 66)

Las alternativas de Illich a la escuela, que se hallan esbozadas en sus

puede determinar qué cosa van a hacer el maestro y el alumno cuando estén juntos en la clase” (Illich, 1975, p. 17). En esto se desmarca tanto de la visión conservadora y liberal como de la izquierda marxista, y constituye el aspecto más aprovechable de su crítica, a juicio de Fernández Enguita: "Ése fue el gran acierto de Illich: captar el hecho de que las profesiones y sus clientelas dependientes (a la vez que la estratificación social del trabajo de acuerdo con la cualificación) forman parte de otra relación de poder, que son otro pilar de desigualdad, sólo que basado en la distribución asimétrica del conocimiento en vez de en los medios de producción o el mando sobre las personas” (Fernández Enguita, 2003, p. 79). No obstante, este mismo autor hace un balance finalmente negativo de la visión del austriaco y de toda crítica a las instituciones (o "burocracias”, en palabras de Illich): “Illich nos ayudó a abrir los ojos ante la dinámica opresiva inherente a la institución escolar y los intereses corporativos de la profesión, pero sin proponer otra respuesta que el retorno imposible a un pasado inexistente. No era una utopía, sino una ucronía. La tarea de quienes creen posible otra educación no estriba en imaginar un implausible mundo desinstitucionalizado, sino en democratizar de arriba abajo unas instituciones de las que no sabríamos prescindir” (Fernández Enguita, 2003, p. 80). 
escritos, pretenden reubicar la educación en su dinamismo y espontaneidad (Illich, 1974, pp. 97-148). Persiguen devolver a la relación educativa su naturaleza de vinculación grata y creativa de los seres humanos entre sí. En general, en palabras de Antoni Tort (2003), Illich propugna "tramas o redes educacionales que aumenten la oportunidad de que cada cual transforme cada momento de sus vidas en un momento de aprendizaje. La transferencia de la responsabilidad de educación hacia las instituciones, señalaba, no deja de ser un suicidio espiritual" (p. 83). Todas sus propuestas, por muy descabelladas que parezcan, se comprenden desde esta idea motriz. Su propósito también puede definirse, según nos esclarece la lectura de uno de sus libros más cercanos en el tiempo, como devolver al ciudadano su espacio vital, donde él pueda desarrollarse y ser persona. Se trata de una reivindicación de la intimidad y del espacio individual donde el sujeto es dueño y creador, que se contrapone al espacio aséptico y racionalizado de las ciudades contemporáneas (y de la escuela) que nos invade (Illich, 1989, pp. 24-29). En los colegios el ámbito impersonal y mecánico se apodera de los sujetos que dejan de serlo, y que se ven obligados a someterse a una racionalidad ajena, la cual parece adquirir vida propia e imponerse a los hombres estableciendo sus reglas.

La crítica de Illich es, en realidad, una crítica a las instituciones que cuadriculan la existencia humana apropiándose de ella. Como afirma él mismo: "Al insistir en un 'espacio' interior me defiendo contra la geometrización de mi intimidad, contra su reducción a una noción algebraica equivalente a un espacio exterior que ha sido reducido a dimensiones cartesianas" (Illich, 1989, p. 47). Pretende esbozar, en este sentido, una sociedad que facilite la expresión y la participación de todas las personas, en espacios culturales aptos para ello. Y en todo esto no hace sino enlazar con una corriente autocrítica de la propia Modernidad. En efecto, la teoría desescolarizadora es, como los movimientos contraculturales de los años sesenta y setenta, una alternativa con raíces en la propia Modernidad, en sus planteamientos más radicales y autocríticos surgidos ya en el propio siglo XVIII con Rousseau, entre otros autores. Creemos que, por tanto, Illich es heredero de una Ilustración que se opone a las consecuencias alienantes de la propia Ilustración. Cuando dialogamos con Illich, lo hacemos con uno de los últimos pensadores utópicos que, desde luego, constituyen una herencia de la modernidad ilustrada, en cuanto razón que se cuestiona a sí misma. 
Pero nuestra civilización tal vez no sea capaz de superar la razón burocrática y conquistadora, antes fuente de alienación y dominio que de emancipación. Quizás nos encaminemos a un cierre escéptico y desencantado de la Ilustración, como ya se palpa desde hace tiempo en el llamado pensamiento postmoderno. La alternativa optimista de Illich, que entronca con una fuerte y dieciochesca fe en el ser humano, se contrapone a la tristeza de la sociedad que anticipa la película Blade Runner o la amargura de las últimas reflexiones de Guillermo en la novela El Nombre de la Rosa de Umberto Eco. Porque quizás la era del vacío (Lipovetsky, 2000) sea, en el fondo, una época triste que se viste de fiesta.

En cualquier caso, la lectura de Illich resulta un ejercicio refrescante y gozoso porque nos transmite esperanza, incitándonos a construir una cultura impregnada de utopía. El hecho de que exista una visión como la suya nos dota de un bello horizonte hacia el que orientarnos, aunque nunca lo alcancemos plenamente. Qué duda cabe que nutrir con su lectura nuestra imaginación nos puede ayudar a entender la educación. Pero hemos de tener muy presente que él nunca pretendió decirnos con exactitud qué debemos hacer. Él nunca quiso trazar un plano detallado de algo llamado "Utopía". Por eso, escribe:

De nada me serviría ofrecer una ficción detallada de la sociedad futura. Quiero dar una guía para la acción y dejar libre curso a la imaginación. La vida dentro de una sociedad convivencial y moderna nos reserva sorpresas que sobrepasan nuestra imaginación y nuestra esperanza. No propongo una utopía normativa, sino las condiciones formales de un procedimiento que permita a cada colectividad elegir continuamente su utopía realizable. (Illich, 1978, p. 32) $\left({ }^{4}\right)$

4 Con belleza afirma esta misma idea en otra obra: "Amigos míos, vuestra tarea es sorprenderos, y que todos nos sorprendamos, ... Nuestra esperanza de salvación descansa en [la disposición a] ser sorprendidos por el Otro. Aprendamos a ser siempre sorprendidos. Yo ya decidí, hace tiempo, esperar nuevas sorpresas hasta el último acto de mi vida, o sea, hasta en la propia muerte." (Illich, 1973, p. 114) 


\title{
Sociedad, Utopía y Educación en Iván Illich
}

Gómez, M. S., (2007). Society, utopia and education in Ivan Illich. Psicologia USP, 17(3), 183-201.

\begin{abstract}
In this essay the author emphasizes the connection between the Ivan Illich critic to schooling and his forceful critic to the consumer society and the automation of human life. The arguments of Illich were revised and connected to some philosophical movements and thinkers of the XX century. These ones also are critical with the ways of life produced by a particular version of the Enlightenment.
\end{abstract}

Index terms: Illich, Ivan. Education. Criticism. Utopias.

Gómez, M. S., (2007). Société, utopie et éducation en Ivan Illich. Psicologia USP, 17(3), 183-201.

Résumé: Dans cet article nous soulignons la connexion entre la critique à la scolarisation d'Ivan Illich et sa critique à la société de consommation et la technification de la vie humaine. Nous révisons leurs arguments et nous mettons eux en rapport avec quelques mouvements philosophiques et penseurs du siècle XX. Cet auteurs aussi sont très critiques avec les modes de vie hérités d'une certaine version de l'Illustration.

Mots clés: Illich, Ivan. Éducation. Critique. Utopie.

\section{Referencias}

Fernández Enguita, M. (2003). Una reconsideración. Cuadernos de pedagogía, (323), 77-80.

Ferrière, A. (1982). La escuela activa (Diorki, ver. castellana). Barcelona, España: Herder.

Freire, P. (1989). La educación como práctica de la libertad (L. Ronzoni, trad.). Madrid: Siglo XXI.

Freire, P. (1992). Pedagogía del oprimido (J. Mellado, trad.). Madrid: Siglo XXI.

Fromm, E. (1976). El miedo a la libertad (G. Germani, trad.). Buenos Aires: Paidós.

Fromm, E. (1994). Prólogo a Neill. In A. S. Summerhill, Un punto de vista radical sobre 


\section{Marcos Santos Gómez}

la educación de los niños (F. M. Torner, trad.. pp. 9-15). Madrid: Fondo de Cultura Económica.

Giroux, H., \& McLaren, P. (1998). Sociedad, cultura y educación (B. Orozco Fuentes, G. T. Gómez, L. M. Quiroz, J. Vivaldo Lima, G. E. Díaz, \& H. Guerrero, trads.). Madrid: Miño y Dávila.

Goodman, P. (1976). La des-educación obligatoria (R. Ribé, trad.). Barcelona, España: Fontanella.

Holt, J. (1982). El fracaso de la escuela (A. Linares, trad.). Madrid: Alianza.

Illich, I. (1973). Celebration of Awareness. A call for institutional revolution. Harmondsworth: Penguin Education.

Illich, I. (1974). La sociedad desescolarizada (G. Espinosa, trad.). Barcelona, España: Barral.

Illich, I. (1975). Conversando con Iván Illich. Cuadernos de Pedagogía, 7, 16-23.

Illich, I. (1978). La convivencialidad (M. P. de Gossmann, trad.). Barcelona, España: Barral.

Illich, I. (1989). $\mathrm{H}_{2} \mathrm{O}$ y las aguas del olvido (J. M. Shert, trad.). Madrid: Cátedra.

Illich, I., \& Freire, P. (1975). Diálogo. Buenos Aires: Búsqueda.

Illich, I., Gintis, H., Greer, C., Postman, N., Gross, R., Fairfield, R. P., et al. (1977). Un mundo sin escuelas (M. A. Pulido, trad.). México: Nueva Imagen.

Lipovetsky, G. (2000). La era del vacío. Ensayos sobre el individualismo contemporáneo (J. Vinyoli \& M. Pendanx, trads.). Barcelona, España: Anagrama.

Neill, A. S. (1994). Summerhill. Un punto de vista radical sobre la educación de los niños (F. M. Torner, trad.). Madrid: Fondo de Cultura Económica.

Neill, A. S. (1999). Hijos en libertad (E. Goligorsky, trad.). Barcelona, España: Altaya.

Paquot, T. (2003, janvier). La résistance selon Ivan Illich. Le monde diplomatique, p. 28. (Versión castellana de la edición española)

Reimer, E. (1981). La escuela ha muerto. Alternativas en materia de educación (E. Mayans, trad.). Barcelona, España: Guadarrama.

Santos, M. (2006a). De la verticalidad a la horizontalidad. Reflexiones para una educación emancipadora. Realidad. Revista de Ciencias Sociales y Humanidades, 107, 39-64.

Santos, M. (2006b). Participación, democracia y educación: cultura escolar y cultura popular. Revista de Educación (Ministerio de Educación, Cultura y Deporte), (339), 883-901.

Spring, J. (1987). Introducción a la educación radical (F. Velasco, trad.). Madrid: Akal.

Tort, A. (2002). Ivan Illich: la desescolarización o la educación sin escuela. In J. Trilla 
(Comp.), El legado pedagógico del siglo XX para la escuela del siglo XXI. Barcelona, España: Graó.

Tort, A. (2003). Los silencios y las palabras de Iván Illich. Cuadernos de Pedagogía, (323), 81-83.

Recebido em: 17/11/2006

Aceito em: 4/12/2006 